\title{
Bicaval versus atrial anastomoses in cardiac transplantation
}

\section{Right atrial dimension and tricuspid valve function at rest and during exercise up to thirty-six months after transplantation}

Conventional cardiac transplantation with atrial anastomoses alters atrial integrity, geometry, and possibly function. Theoretically, this may also contribute to the development of tricuspid insufficiency that is frequently observed after the operation. Thus more anatomic transplantation techniques using bicaval anastomoses were recently introduced into clinical practice. Knowledge of their efficacy, however, is scarce. Therefore right atrial size and tricuspid valve function were compared in patients with bicaval (group A) and standard atrial (group B) anastomoses in a randomized, prospective study. The results of this echocardiographic study at rest and exercise in 18 patients (bicaval $n=8$; atrial $n=10$ ) on the average 28 months after transplantation are presented. The right atrial dimension was comparable between group A patients and control subjects and larger in group B patients $(p<0.05)$. The incidence of tricuspid regurgitation was not different between the two groups at rest, but it was at exercise $(50$ watts of workload) $(p<0.05)$. This study suggests that up to 36 months after cardiac transplantation the technique of bicaval in contrast to atrial anastomoses preserves right atrial size and reduces tricuspid regurgitation during exercise. Whether this leads to improved hemodynamics and increased exercise capacity remains to be evaluated in a larger series of patients. (J THORAC CARDIOVASC SURG 1994;108:780-4)

H. H. Sievers, MD, ${ }^{a}$ R. Leyh, MD, ${ }^{a}$ A. Jahnke, MD, ${ }^{a}$ A. Petry, MD, ${ }^{b}$ E. G. Kraatz, MD, ${ }^{a}$

G. Herrmann, MD, ${ }^{\mathrm{c}}$ R. Simon, MD, ${ }^{\mathrm{c}}$ and A. Bernhard, MD, ${ }^{\mathrm{a}}$ Kiel, Germany

$\mathrm{C}$ ardiac transplantation has become a routine and effective method for treating end-stage heart disease. The standard surgical technique based on the descriptions of Cass and Brock ${ }^{1}$ and Lower and Shumway ${ }^{2}$ consists of two atrial and two arterial anastomoses. Although this method is attractive in its simplicity and effectiveness, it alters atrial geometry and may adversely affect atrioventricular valve function. This assumption is sup-

From the Departments of Cardiovascular Surgery, ${ }^{a}$ Anaesthesiology, ${ }^{b}$ and Cardiology, ${ }^{c}$ University of Kiel, Kiel, Germany.

Received for publication June 21, 1993.

Accepted for publication June 16, 1994.

Address for reprints: H. H. Sievers, MD, Klinik für Herzchirurgie, Medizinische Universität Lübeck, Ratzeburger Allee 160, 23538 Lübeck, Germany.

Copyright ${ }^{(} 1994$ by Mosby-Year Book, Inc.

$0022-5223 / 94 \$ 3.00+0 \quad \mathbf{1 2} / \mathbf{1} / \mathbf{5 8 4 2 1}$ ported by Angermann and associates, ${ }^{3}$ who reported a high rate of especially tricuspid valve incompetence in long-term survivors after standard cardiac transplantation probably related to abnormal right atrial size and function.

Thus the hypothesis was that an alternative technique with bicaval anastomoses preserving the right atrium intact, as described for experimental cardiac transplantation by Goldberg, Berman, and Akman, ${ }^{4}$ may provide better tricuspid valve function. Although interest in a more physiologic, refined approach to cardiac transplantation is increasing, ${ }^{5-7}$ the influence of this alternative technique on right atrial size and tricuspid valve function has not been well delineated. This report describes the intermediate-term results of a prospective, randomized study on right atrial size and tricuspid valve function at rest and during exercise, comparing the method of standard atrial with bicaval anastomoses in cardiac transplantation. 
Table I. Baseline characteristics of 24 patients who were entered into the study and 18 follow-up patients available for echo investigation (in parentheses)

\begin{tabular}{|c|c|c|c|}
\hline & $\begin{array}{l}\text { Group A } \\
\text { (bicaval): } \\
\mathrm{n}=12(8)\end{array}$ & $\begin{array}{c}\text { Group B } \\
\text { (atrial): } \\
\mathrm{n}=I 2(10)\end{array}$ & p Value \\
\hline Diagnosis & & & NS(NS) \\
\hline $\begin{array}{l}\text { Ischemic } \\
\quad \text { cardiomyopathy }(n)\end{array}$ & $5(5)$ & $5(5)$ & \\
\hline $\begin{array}{l}\text { Dilative } \\
\quad \text { cardiomyopathy }(n)\end{array}$ & $7(3)$ & $7(5)$ & \\
\hline Gender & & & $\mathrm{NS}(\mathrm{NS})$ \\
\hline Female $(n)$ & $2(1)$ & $3(3)$ & \\
\hline Male $(n)$ & $10(7)$ & $9(7)$ & \\
\hline $\begin{array}{l}\text { PVR } \\
\qquad\left(\text { dyne } \cdot \mathrm{sec} \cdot \mathrm{cm}^{-5}\right)\end{array}$ & $195.3 \pm 98.8$ & $145.1 \pm 85.4$ & NS \\
\hline & $(176.8 \pm 84.2)$ & $(193.6 \pm 95.7)$ & NS \\
\hline Age $(y r)$ & $\begin{array}{c}55.5 \pm 9.3 \\
(56.3 \pm 9.5)\end{array}$ & $\begin{array}{c}50.8 \pm 12.5 \\
(49.7 \pm 13.1)\end{array}$ & $\begin{array}{l}\text { NS } \\
\text { NS }\end{array}$ \\
\hline Donor age $(\mathrm{yr})$ & $\begin{array}{c}35.7 \pm 13.2 \\
(33.7 \pm 13.8)\end{array}$ & $\begin{array}{c}38.5 \pm 10.6 \\
(40.5 \pm 9.5)\end{array}$ & $\begin{array}{l}\text { NS } \\
\text { NS }\end{array}$ \\
\hline $\begin{array}{l}\text { Total ischemic } \\
\text { time (min) }\end{array}$ & $\begin{array}{c}210.3 \pm 41.1 \\
(226.8 \pm 42.0)\end{array}$ & $\begin{array}{c}154.4 \pm 65.7 \\
(145.6 \pm 58.9)\end{array}$ & $\begin{array}{l}\mathrm{S} \\
\mathrm{S}\end{array}$ \\
\hline
\end{tabular}

$P V R$, Pulmonary vascular resistance; $N S$, not significant; $S$, significant.

\section{Patients and methods}

Patients. Between October 1989 and October 1990 all 24 consecutive patients who underwent orthotopic cardiac transplantation for end-stage cardiac failure were entered into the study. They were randomly assigned to receive bicaval anastomoses (group A, $n=12$ ) or atrial anastomoses (group B, $n=12$ ). The study was approved by the appropriate institutional review board. Informed consent was obtained from each patient. Patient characteristics did not differ significantly between the two groups except for the total ischemic time of the donor heart (Table I). There were no hospital deaths. During the interval from operation to study four patients with bicaval anastomoses died of malignant diseases. In the atrial group one patient required retransplantation because of chronic rejection 12 months after the first transplantation and one patient refused the echocardiographic investigation. Characteristics of the remaining patients, who constitute the present study population, are summarized in Table II. At the echo investigation five patients in group $A$ and five in group $B$ were in New York Heart Association functional class I, three patients in group $\mathrm{A}$ were in class I to II, and five patients in group B were in class II. The control group for comparison of the atrial dimension consisted of one female and 11 male volunteers in whom by history, clinical examination, and standard echocardiography no cardiac valve abnormalities could be detected. Age range of these control subjects was 37 to 68 years (mean $56.6 \pm 9.4$ years), weight range 48 to $90 \mathrm{~kg}$ (mean $73.6 \pm 14.5 \mathrm{~kg}$ ), and height range 156 to $176 \mathrm{~cm}$ (mean $170.0 \pm 6.7 \mathrm{~cm}$ ). These data were not different from those of the patients $(p>0.05)$.

Operative technique. Standard cardiopulmonary bypass with a membrane oxygenator at a nasopharyngeal temperature of $24^{\circ} \mathrm{C}$ was used. Bicaval cannulation as distally as possible is important for proper caval anastomoses without tension, torsion,
Table II. Characteristics of 18 patients available for postoperative echocardiographic investigation .

\begin{tabular}{|c|c|c|c|}
\hline & $\begin{array}{c}\text { Group } A \\
\text { (bicaval): } \\
\mathrm{n}=8\end{array}$ & $\begin{array}{c}\text { Group } B \\
\text { (atrial): } \\
\mathrm{n}=10\end{array}$ & $\mathrm{p}$ Value \\
\hline \multicolumn{4}{|l|}{ Before study } \\
\hline Biopsies per patient & $29.3 \pm 11.8$ & $30.5 \pm 7.6$ & NS \\
\hline Treated infections & $n=3$ & $n=2$ & NS \\
\hline $\begin{array}{l}\text { Treated rejections } \\
\text { (1/patient })\end{array}$ & 1.6 & 1.5 & NS \\
\hline \multicolumn{4}{|l|}{ At study } \\
\hline Age (yr) & $57.3 \pm 9.8$ & $52.1 \pm 13.2$ & NS \\
\hline Weight $(\mathrm{kg})$ & $84.2 \pm 15.5$ & $82.3 \pm 21.8$ & NS \\
\hline Height $(\mathrm{cm})$ & $173.9 \pm 7.0$ & $175.3 \pm 9.3$ & NS \\
\hline $\begin{array}{l}\text { PVR }\left(\text { dyne } \cdot \mathrm{sec} \cdot \mathrm{cm}^{-5} \text { ) }\right. \\
\text { at rest }\end{array}$ & $153.2 \pm 18.7$ & $149.5 \pm 16.9$ & NS \\
\hline $\begin{array}{l}\text { PVR }\left(\text { dyne } \cdot \mathrm{sec} \cdot \mathrm{cm}^{-5}\right) \\
\text { at } 50 \text { watts }\end{array}$ & $113.4 \pm 30.3$ & $108.7 \pm 23.2$ & NS \\
\hline \multicolumn{4}{|l|}{ Heart rate (beats/min) } \\
\hline At rest & $91.0 \pm 8.1$ & $91.4 \pm 10.8$ & NS \\
\hline At 50 watts of workload & $113.8 \pm 7.2$ & $114.5 \pm 5.9$ & NS \\
\hline At 75 watts of workload & $130.0 \pm 9.8$ & $123.2 \pm 5.3$ & NS \\
\hline At 100 watts of workload & $144.2 \pm 12.0$ & $137.7 \pm 15.4$ & NS \\
\hline
\end{tabular}

$P V R$, Pulmonary vascular resistance; $N S$, not significant.

or obstruction. The recipient heart is excised with a $10 \mathrm{~mm}$ wide atrial cuff at the inferior vena cava and the whole length of the superior vena cava. Exact trimming is performed with respect to the dimensions of the donor heart. Only a small posterior cuff of the left atrium combining the pulmonary venous ostia is left in place. ${ }^{8}$ After excision of a corresponding part from the donor left atrium, the implantation starts with the left atrial anastomosis as done in the standard technique. We prefer an intraluminal everting continuous suture technique with 3-0 polypropylene to reduce the risk of thrombus formation at the suture line. For anastomoses of the inferior vena cava 4-0 polypropylene running sutures were used, and for those of the superior vena cava 5-0 polypropylene interrupted sutures were used.

Measurement of hemodynamics. Before the echo study a thermodilution right ventricular catheter $(93 \mathrm{~A}-431 \mathrm{H}-7.5$, Baxter Healthcare Corp., Santa Ana, Calif.) was positioned in the pulmonary artery. The thermistor from this catheter was connected to a computer (REF-1, Baxter), which computed cardiac output. Additionally, the mean pulmonary artery and the pulmonary capillary wedge pressures were obtained and the pulmonary vascular resistance was calculated as previously described. ${ }^{9}$ The preoperative pulmonary vascular resistance was determined likewise from pressure data obtained at right heart catheterization performed less than 6 months before transplantation without special vasodilator medication.

Immunosuppression. Immunosuppression was accomplished with a regimen that included steroids, rabbit antithymocyte globulin, cyclosporine, and azathioprine. Rejection episodes were not different between the two groups (see Table II).

Ultrasound examination. Patients with bicaval anastomoses were investigated $28.4 \pm 7.4$ months after transplantation and those with atrial anastomoses $28.6 \pm 3.2$ months $(p>0.05)$ after transplantation by an experienced echocardiographer blinded to the surgical technique. A mechanical sector scanner 


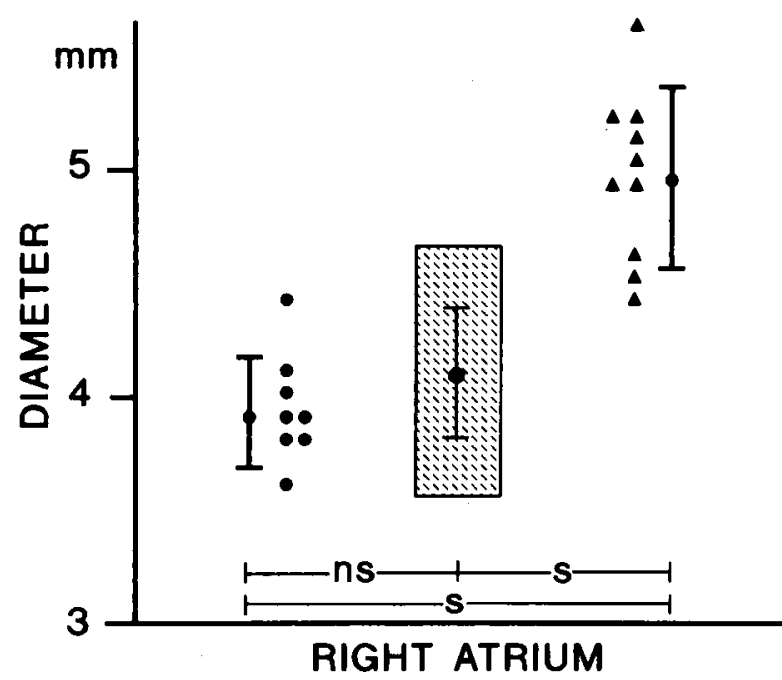

Fig. 1. Diameter of the right atrium measured echocardiographically up to 36 months after cardiac transplantation performed with bicaval (left column, circles) and atrial anastomoses (right column, triangles). The diameter after bicaval anastomoses was not different ( $n s$ ) from that of the control group (middle column, shaded area). The diameter after standard atrial anastomoses was significantly $(s)$ larger than in the control and bicaval groups.

(Aloka 870 SSD, Aloka Co. Ltd., Tokyo, Japan) and a 3.5 MHz transducer were used. All echoimages were permanently recorded on a $3 / 4$-inch Sony videotape (U-Matic, Sony Corporation, Tokyo, Japan). Doppler windows were apical and subcostal four-chamber views for the tricuspid valve. ${ }^{10}$ The orientation of the jet of blood and the regurgitation through the tricuspid valve were evaluated by color flow mapping followed by pulsed and continuous-wave Doppler echocardiography. The degree of tricuspid insufficiency was estimated semiquantitatively by color flow mapping. " Grading was as follows ${ }^{1}$ : Grade I-the regurgitant flow reaches within half of the long axis of the right atrium; grade II-the flow has passed the halfway point but without significant regurgitation in the hepatic vein; grade III-the flow extends beyond the halfway point of the long axis of the right atrium, with significant regurgitation in the hepatic vein. The apical four-chamber view was used for the measurement of right atrial diameter perpendicular to the plane of the tricuspid orifice. Stress echocardiography of the tricuspid valve was performed with the patient in the supine position immediately after exercise at different work rates. Only high-quality echocardiograms with the heart beating in sinus rhythm were evaluated.

Exercise protocol. After routine myocardial biopsy, hemodynamic measurements and echo investigation at rest were carried out. The histologic examination of the biopsy specimens revealed no signs of significant rejection. Exercise testing was performed in a supine exercise unit (Siemens $870 \mathrm{~L}$, Siemens, Erlangen, Germany) starting with 25 watts after a period of at least 30 minutes of rest. Every 5 minutes the workload was increased by 25 watts until exhaustion or achievement of 100 watts. During exercise the electrocardiogram was monitored continuously.

Statistics. Data are summarized as the mean \pm 1 standard deviation. The difference in data between the groups of patients and the control subjects was tested by the Wilcoxon/MannWhitney $U$ test. For comparison of two relative frequencies the exact Fisher test of independence was applied. Values of $p \leq 0.05$ were considered significant. Because the number of patients was small and bicaval anastomoses are newly introduced into clinical practice, a type II error (i.e., $\leq 0.05$ ) with less serious consequences was chosen, accepting the risk that an invalid null hypothesis was retained. Thus the conclusion that no significant differences exist must then be considered with caution. To indicate the power of the study, the chance, for example, of detecting the difference of 0.5 between the two groups regarding the incidence of tricuspid insufficiency at 50 watts of workload is about $70 \%$ with a significance level of $5 \%$.

Limitations. Assessment of regurgitation volume from jet size by Doppler color flow mapping has potential limitations related to the physiology and hydraulics of the regurgitant flow, the physical nature of ultrasound, and the technique of measurement. ${ }^{12}$ Thus it must be taken into consideration that this technique allows for semiquantitatively estimating valvular regurgitation only. Nevertheless, Doppler color flow imaging represents a useful tool for detecting and evaluating tricuspid regurgitation noninvasively and was found to be more sensitive than contrast echocardiography when compared with the standards for quantitation of tricuspid regurgitation like fast Fourier transformation frequency analysis or right ventriculography. ${ }^{13}$ Another limitation that is difficult to rule out exists because of the absence of information regarding tricuspid valve function of the donor heart in its original position and function. Also, six of 24 patients who were entered in to the study were not available for the echo study and may bias the results. However, death of the four patients in group $A$ and the indication for retransplantation of the heart in one patient in group $B$ were not related to the surgical technique or to tricuspid regurgitation. A previous echo study 4 months after the operation revéaled a tricuspid regurgitation grade $0(n=2)$ and $\mathrm{I}(n=2)$ in the four group A patients and grade 0 and II in the two patients lost to follow-up in group B. Randomization was carried out by alternately assigning the patients to the different surgical techniques. Although this type of allocation of patients represents a practiced method in applied statistics, ${ }^{14}$ random numbers were not used.

\section{Results}

Echocardiographic data are depicted in Figs. 1 to 3. The right atrial dimension was larger in group B than in group A and the control group ( $p<0.05$, Fig. 1). The incidence of tricuspid regurgitation at rest was not significantly different between the two groups, although more patients with tricuspid regurgitation were in group B (Figs. 2 and 3). However, the increase of tricuspid regurgitation from rest to 50 watts of workload was more pronounced in group B ( $p<0.05$, Figs. 2 and 3) and thus tricuspid regurgitation at 50 watts of workload was more prevalent in patients with atrial anastomoses $(p<0.05)$. This study could not demonstrate a significantly higher exercise capacity in group A patients although seven of eight patients reached 75 watts of workload in group A and only five of 10 patients in group B (Figs. 2 and 3). 


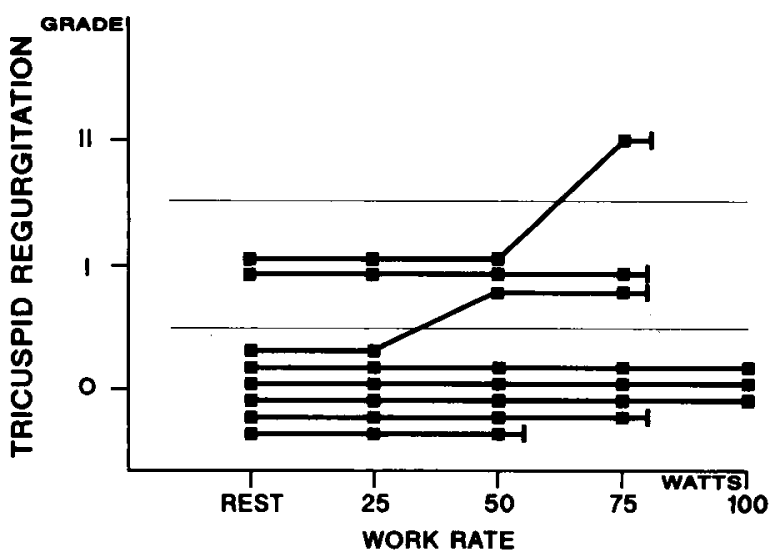

Fig. 2. Tricuspid regurgitation as judged by echocardiography at rest and during exercise at different workloads up to 36 months after cardiac transplantation in patients with bicaval anastomoses.

\section{Discussion}

Tricuspid regurgitation frequently occurs after conventional cardiac transplantation. ${ }^{3,15-20}$ Several causes are possibly related to its development. Subject to these are the pulmonary artery resistance at rest and during exercise, ${ }^{3,17-21}$ the size mismatch between donor and recipient hearts, ${ }^{17,18}$ roughly assessable by the preoperative diagnosis for transplantation, the duration of allograft ischemia ${ }^{17,21}$ and significant rejection episodes followed by interstitial fibrosis. ${ }^{17,22}$ Also heart rate at the time of the echo study may influence estimation of regurgitant jet size. ${ }^{23}$ In the present study all of these parameters that may promote tricuspid insufficiency were evaluated and found to be equally distributed in patients randomly assigned for bicaval or standard anastomoses (Tables I and II), except for the longer total ischemic time of the donor organ in the bicaval group. This would favor the occurrence of tricuspid regurgitation in patients with bicaval anastomoses, which was, however, not the case. On the contrary, a higher degree of tricuspid regurgitation was found in patients with standard atrial anastomoses, and this difference achieved statistical significance at exercise. These observations suggest that the higher degree of tricuspid insufficiency in patients with the standard atrial anastomoses may be associated with the surgical technique itself. In this context the right atrial size, which was significantly enlarged in patients with standard atrial anastomoses (see Fig. 1), probably contributes to the development of tricuspid regurgitation by increasing wall tension and tricuspid annular size during late systole, as was reported by Tei and associates. ${ }^{24}$ For logistical reasons right heart hemodynamics were not available.

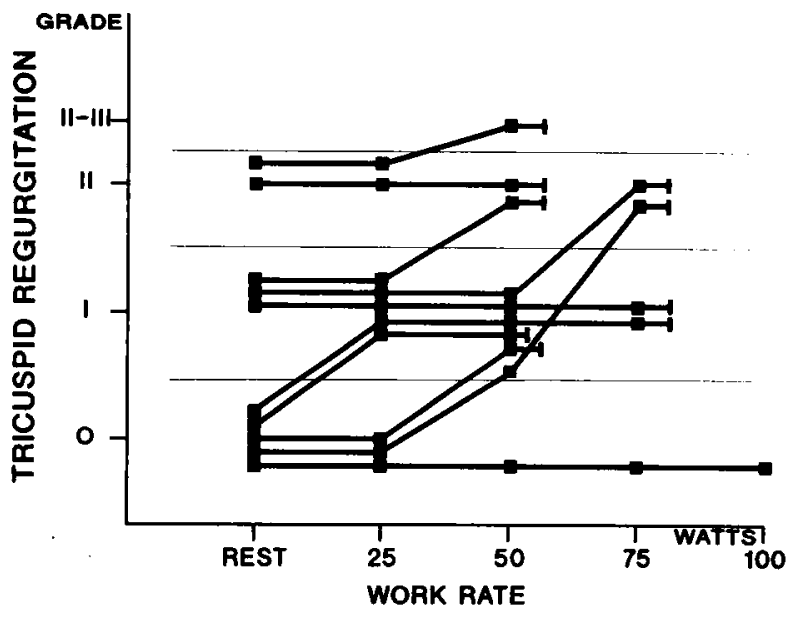

Fig. 3. Tricuspid regurgitation as judged by echocardiography at rest and during exercise at different workloads up to 36 months after cardiac transplantation in patients with standard atrial anastomoses.

Preliminary results of a more recent study conducted to evaluate this topic, however, suggest that the right atrial pressure significantly increases during exercise in patients with atrial anastomoses. This would further raise wall tension of the enlarged right atrium and favor the development of tricuspid insufficiency during exercise.

Isolated tricuspid insufficiency rarely causes symptoms. However, in group A patients with the lower incidence of tricuspid regurgitation during exercise, seven of eight patients reached 75 watts in contrast to five of 10 patients in group B, with atrial anastomoses and the higher likelihood of tricuspid regurgitation (see Figs. 2 and 3). Furthermore, only patients without tricuspid regurgitation were able to achieve 100 watts of workload, providing some evidence that tricuspid insufficiency in the setting of cardiac transplantation may influence exercise capacity. Whether the observed relation between the degree of tricuspid regurgitation and exercise capacity and thus a functional benefit of the bicaval technique will assume statistical significance remains to be established in a larger series of patients.

Clotting of the bicaval anastomoses as a potential disadvantage of this technique was not observed clinically or by echocardiography. In the contrary, spontaneous echoes at atrial suture lines, which are suggestive of thrombus formation, were not found in the right atrium of patients with bicaval anastomoses.

Another potential concern of the bicaval technique, namely, the longer total ischemic time, could be substantially reduced in the last cases by performing the caval anastomoses during reperfusion of the donor heart. 
In conclusion, bicaval anastomoses may have some advantages over atrial anastomoses in cardiac transplantation, inasmuch as this alternative surgical technique preserves the size of the right atrium and improves tricuspid valve function, especially during exercise.

\section{REFERENCES}

1. Cass MH, Brock R. Heart excision and replacement. Guys Hosp Rep 1959;108:285-90.

2. Lower RR, Shumway NE. Studies in orthotopic homotransplantation of the canine heart. Surg Forum 1960;11: 18-9.

3. Angermann CE, Spes $\mathrm{CH}$, Tammen A, et al. Anatomic characteristics and valvular function of the transplanted heart: transthoracic versus transesophageal echocardiographic findings. J Heart Transplant 1990;9:331-8.

4. Goldberg M, Berman EF, Akman LC. Homologous transplantation of the canine heart. J Int Coll Surg 1958;30:57586.

5. Dreyfus G, Jebara V, Mihaileanu S, Carpentier AF. Total orthotopic heart transplantation: an alternative to the standard technique. Ann Thorac Surg 1991;52:1181-4.

6. Banner NR, Khaghani A, Fitzgerald M, Mitchell AG, Radley-Smith R, Yacoub MH. The expanding role of cardiac transplantation. In: Unger F, ed. Assisted circulation, 3rd ed. Berlin: Springer, 1989:448-67.

7. Kendall SWH, Ciulli F, Mullins PA, Biocina B, Dunning JJ, Large SR. Total orthotopic heart transplantation: an alternative to the standard technique. Ann Thorac Surg 1992;54:187.

8. Sievers HH, Weyand M, Kraatz EG, Bernhard A. An alternative technique for orthotopic cardiac transplantation, with preservation of the normal anatomy of the right atrium. Thorac Cardiovasc Surg 1991;39:70-2.

9. Bourge RC, Kirklin JK, Naftel DC, White C, Mason DA, Epstein AE. Analysis and predictors of pulmonary vascular resistance after cardiac transplantation. J THORAC Cardiovasc Surg 1991;101:432-45.

10. Henry WL, DeMaria A, Gramiak R, et al. Standards and nomenclature: report of the American Society of Echocardiography. In: Schapira JN, Herold JG, ed. Two-dimensional echocardiography and cardiac Doppler. Baltimore: Williams \& Wilkins, 1990:57-62.

11. Omoto R. 2-D Doppler findings in valvular regurgitation. In: Omoto R, ed. Color atlas of realtime two-dimensional Doppler echocardiography. 2nd ed. Tokyo: Shindan-ToChiryo (distributed by Lea \& Febiger), 1987:69.

12. Sahn DJ. Instrumentation and physical factors related to visualization of stenotic and regurgitant jet by Doppler color flow imaging. J Am Coll Cardiol 1988;12:1354-65.

13. Suzuki Y, Kambara H, Kadota K, et al. Detection and evaluation of tricuspid regurgitation using a realtime, twodimensional, color-coded, Doppler flow imaging system: comparison with contrast two-dimensional echocardiography and right ventriculography. Am J Cardiol 1986;57: $811-5$.

14. Sachs L. Applied statistics. 5th ed. New York: Springer, 1982:210-4.

15. Lewen MK, Bryg RJ, Miller LW, Williams GA, Lobowitz AJ. Tricuspid regurgitation by Doppler echocardiography after orthotopic cardiac transplantation. Am J Cardiol 1987;59:1371-4.

16. Cladellas M, Abadal ML, Pons-Llado G, Ballester M. Early transient multivalvular regurgitation detected by pulse wave Doppler echocardiography. Am J Cardiol 1986;58:1122-4.

17. Herrmann G, Simon R, Haverich A, et al. Left ventricular function, tricuspid incompetence, and incidence of coronary artery disease late after orthotopic heart transplantation. Eur J Cardiothorac Surg 1989;3:111-8.

18. Haverich A, Albes JM, Fahrenkamp G, Schäfers HJ, Wahlers T, Heublein B. Intraoperative echocardiography to detect and prevent tricuspid valve regurgitation after heart transplantation. Eur J Cardiothorac Surg 1991;5:41. 5.

19. Bhatia SJ, Kirshenbaum JM, Shemin RJ, et al. Time course of reduction of pulmonary hypertension and right ventricular remodeling after orthotopic cardiac transplantation. Circulation 1987;76:819-26.

20. Young JB, Leon CA, Short D, et al. Evolution of hemodynamics after orthotopic heart and heart-lung transplantation: early restrictive patterns persisting in occult fashion. J Heart Transplant 1987;6:34-43.

21. Lewen MK, Bryg RJ, Miller LW, Williams GA, Lobovitz AJ. The development of tricuspid regurgitation after orthotopic cardiac transplant. J Am Coll Cardiol 1986;7:917.

22. Humen DP, McKenzie FN, Kostuk WJ. Restricted myocardial compliance one year following cardiac transplantation. J Heart Transplant 1984;3:341-4.

23. Cape EG, Yoganathan AP, Levine RA. Increased heart rate can cause underestimation of regurgitant jet size by Doppler color flow mapping. J Am Coll Cardiol 1993;21: 1029-37.

24. Tei C, Pulgrim JP, Shah PM, Ormiston JA, Wong M. The tricuspid valve annulus: study of size and motion in normal subjects and in patients with tricuspid regurgitation. Circulation 1982;66:665-71. 